\title{
Structure and activity of lobophorins from a turrid mollusk-associated Streptomyces sp
}

\author{
Zhenjian Lin ${ }^{1}$, Michael Koch², Christopher D Pond ${ }^{2}$, Gaiselle Mabeza ${ }^{3}$, Romell A Seronay ${ }^{3}$, \\ Gisela P Concepcion ${ }^{3}$, Louis R Barrows ${ }^{2}$, Baldomero M Olivera ${ }^{4}$ and Eric W Schmidt ${ }^{1,4}$
}

A novel lumun-Iumun sampling methodology was used to obtain a large diversity of micromollusks, including the new species Lienardia totopotens. In turn, from L. totopotens we cultivated a Streptomyces sp. strain that contained new and known spirotetronate polyketides, lobophorins (1-5). The structures were elucidated using spectroscopy, and the compounds were evaluated for cytotoxicity to human cells and activity against Mycobacterium tuberculosis, Bacillus subtilis, Pseudomonas aeruginosa and Burkholderia cepacia. Compounds 2-5 showed varying degrees of activity against human cells, M. tuberculosis and $B$. subtilis in the low $\mu \mathrm{m}$ to mid nм range but were inactive against the other strains, while 1 lacking digitoxose was inactive. Very slight structural changes in 2-5 led to varying antibacterial:cytotoxicity ratios, providing a possible basis to synthesize more selective derivatives.

The Journal of Antibiotics (2014) 67, 121-126; doi:10.1038/ja.2013.115; published online 13 November 2013

Keywords: cone snail; Mycobacterium tuberculosis; Streptomyces

\section{INTRODUCTION}

There is an urgent need for new antibiotics to combat the rise of resistant strains. ${ }^{1}$ As an important example, Mycobacterium tuberculosis infects $1 / 3$ of the global population and kills 1.4 million people annually. ${ }^{2}$ The rate of $M$. tuberculosis drug resistance is steadily rising, progressing from multiple drug-resistant forms to extremely drugresistant and finally totally drug-resistant forms. ${ }^{3}$ Natural products represent a major group of successful antituberculosis drugs, including the first-line therapy, rifampicin. Natural products also continue to provide leads for antimycobacterial therapy, ${ }^{4}$ indicating that the natural world should still be examined as a source for new antituberculosis drugs. In addition, further therapies are needed to combat difficult infections, such as drug-resistant Pseudomonas. ${ }^{5}$

A problem with natural product-based antibiotic discovery programs is that the rediscovery rate can be high. ${ }^{4}$ It is straightforward to screen for antibiotic activity, and such screens have been ongoing for about 80 years. Several novel strategies have been suggested to overcome this problem. One approach is to seek novel habitats for bacteria that have not been previously well explored, with the as-yet unproven expectation that new compounds are more likely to be discovered. For this reason, we have been examining bacterial associates of gastropod mollusks, especially from the Family Conidae, which have yielded many novel isolates with novel chemistry. ${ }^{6-10}$ Many of the bacteria cultivated from gastropods probably reflect the microbiology of the surrounding environment, ${ }^{11}$ but at least some of these bacteria are long-term associates that produce compounds important to the mollusks. ${ }^{9}$ Thus, cultivation of mollusk-associated bacteria leads to a library of diverse bacteria, some of which produce new, bioactive natural products.

Symbiotic bacteria from animals provide a good and relatively untapped source of new natural products, but obtaining diverse, novel animals can be time consuming and expensive. We have employed an approach to easily access a large diversity of mollusks, lumun-lumun. ${ }^{12}$ This method, invented and widely used by fishermen in the central Visayan region of the Philippines, involves placing bundles of nets (lumun-lumun) in the sea for 1-6 months. When the nets are harvested, they are found to contain a large abundance and diversity of micromollusks, which are valuable to collectors. In addition, the obtained micromollusks are often novel species, previously unknown to science. ${ }^{13-15}$ Conoidean mollusks, the turrids, are related to cone snails and are overrepresented in these nets. ${ }^{16}$ Turrids are the most speciose of the cone-related mollusks. Ongoing research shows that, like cone snails, each turrid contains a wealth of novel venom peptides that are neuroactive and potentially have other activities. ${ }^{12}$

Although many turrids are found in a single net, we carefully first examined a small subset of these turrids to explore their potential for production of novel microbial natural products. In particular, a new species, Lienardia totopotens, ${ }^{13}$ was found in a lumun-lumun net, dissected and used to obtain novel venoms with potential in drug

${ }^{1}$ Department of Medicinal Chemistry, L.S. Skaggs Pharmacy Institute, University of Utah, Salt Lake City, UT, USA; ${ }^{2}$ Department of Pharmacology and Toxicology, University of Utah, Salt Lake City, UT, USA; ${ }^{3}$ Marine Science Institute, University of the Philippines Diliman, Quezon City, Philippines and ${ }^{4}$ Department of Biology, University of Utah, Salt Lake City, UT, USA

Correspondence: Professor EW Schmidt, Department of Medicinal Chemistry, The University of Utah, 30 South 2000 East, Room 307 , Salt Lake City, UT 84112, USA. E-mail: ews1@utah.edu

We are grateful to Professor Christopher Walsh for his inspiring studies of natural products and for his profound impact on the development of our field

Received 29 July 2013; revised 7 October 2013; accepted 11 October 2013; published online 13 November 2013 
discovery. Tissues were obtained, crushed and plated on microbial media. We previously reported a structurally relatively novel compound from one of these bacterial strains, but unfortunately we could not determine the activity of the compound. ${ }^{8}$ Here, we report a series of less novel compounds, which are in fact relatively trivial new derivatives of the lobophorin series. ${ }^{17-20}$ These compounds were inhibitory to Bacillus subtilis, M. tuberculosis and human CEM-TART cell lines, but not to Pseudomonas aeruginosa or Burkholderia cepacia.

\section{RESULTS}

Strain Streptomyces sp. 1053U.I.1a.3b was cultivated from dissected hepatopancreas tissues of $L$. totopotens, a new species of conoidean mollusk, which was found in a lumun-lumun net in the Philippines. Crude extracts of 1053U.I.1a.3b were active in an antibacterial assay against B. subtilis. High-performance liquid chromatography (HPLC) analysis showed that the strain produced a series of related families of metabolites, which were further purified by bioassay-guided fractionation to yield compounds $\mathbf{1 - 5}$ (Figure 1). Using NMR and mass spectrometry, three compounds were shown to be identical to the previously reported lobophorins $\mathrm{F}(\mathbf{3}),{ }^{19} \mathrm{~B}(\mathbf{4}){ }^{17}$ and C (5), ${ }^{18}$ while the remaining two compounds had not been previously described and were named as lobophorin $\mathrm{H}(\mathbf{1})$ and I (2).

The molecular formula of 1 was established as $\mathrm{C}_{42} \mathrm{H}_{60} \mathrm{~N}_{2} \mathrm{O}_{10}$ by high-resolution electrospray ionization mass spectrometry (HRESIMS) $\left(m / z 753.4344\right.$ for $\left.[\mathrm{M}+\mathrm{H}]^{+}\right)$. Interpretation of the ${ }^{1} \mathrm{H}$ and ${ }^{13} \mathrm{C} \mathrm{NMR}$ spectra (Table 1 and Supplementary Figures S1-S6) showed that 1 has structural features that are almost identical to those of $\mathbf{5}$ (Supplementary Table S1), including a sugar and a complex, highly oxygenated aglycone. 1D and 2D NMR data of 1 supported a lack of three sugar units (A-C) in comparison with 5 (Table 1). Indeed, only one hemiacetal group $\left(\delta_{\mathrm{H}} 4.75, \mathrm{H}-\mathrm{D} 1, \delta_{\mathrm{C}} 96.7, \mathrm{C}-\mathrm{D} 1\right)$ was observed and assigned as the anomeric carbon of a sugar unit. Moreover, the ${ }^{1} \mathrm{H}-{ }^{1} \mathrm{H}$ COSY correlations between $\mathrm{H}-\mathrm{D} 6 / \mathrm{H}-\mathrm{D} 5$ and $\mathrm{H}-\mathrm{D} 1 / \mathrm{H}-\mathrm{D} 2$, together with the heteronuclear multiple-bond correlation spectroscopy (HMBC) correlations from H-D7 to C-D2, D3, D4, and from both $\mathrm{H}-\mathrm{D} 9$ and $\mathrm{H}-\mathrm{D} 4$ to a carbonyl at C-D8 confirm the presence of sugar unit D. This sugar has ${ }^{1} \mathrm{H}$ and ${ }^{13} \mathrm{C}$ chemical shifts that are identical to those of the same sugar found in 5 . The $\mathrm{C}-9{ }^{13} \mathrm{C}$ chemical shift $\left(\delta_{\mathrm{C}} 74.9\right)$ in 1 indicated a free secondary alcohol group instead of the $\mathrm{O}$-glucosidic bond that is found in 5. A comprehensive interpretation of HSQC, COSY and HMBC correlations (Figure 2) performed on $\mathbf{1}$ led to the identification of the key features of the aglycon of 5 . The only exceptions were three quaternary carbons (C-1, $\delta_{\mathrm{C}} 168.4 ; \mathrm{C}-2, \delta_{\mathrm{C}} 103.1$; and C-26, $\left.\delta_{\mathrm{C}} 197.6\right)$, which were observed in the ${ }^{13} \mathrm{C}$ NMR spectrum of 1 but lacked 2D NMR correlations. These were assigned to the tetronic acid core of the aglycon based upon similarity to the chemical shifts found in related compounds. On the basis of these data, the structure of $\mathbf{1}$ was identified as the aglycon of $\mathbf{5}$.

The molecular formula of 2 was determined as $\mathrm{C}_{61} \mathrm{H}_{88} \mathrm{~N}_{2} \mathrm{O}_{21}$ by HRESIMS $\left(m / z 1185.5962\right.$ for $\left.[\mathrm{M}+\mathrm{H}]{ }^{+}\right)$and ${ }^{1} \mathrm{H}$ and ${ }^{13} \mathrm{C}$ NMR data (Table 1 and Supplementary Figures S7-S11). As with 1, a complete set of 2D NMR data were used to elucidate the structure of 2 and to confirm its relationship to compound 1 (Figure 2). In comparison with 1 , compound 2 has three more sugar units, which were deduced by the observation of three more hemiacetal groups $\left(\delta_{\mathrm{H}} 4.75, \mathrm{H}-\mathrm{A} 1\right.$, $\delta_{\mathrm{C}} 100.3, \mathrm{C}-\mathrm{A} 1 ; \delta_{\mathrm{H}} 5.18, \mathrm{H}-\mathrm{B} 1, \delta_{\mathrm{C}} 93.97, \mathrm{C}-\mathrm{B} 1$; and $\delta_{\mathrm{H}} 4.94, \mathrm{H}-\mathrm{C} 1, \delta_{\mathrm{C}}$ 101.4, C-C1). The carbon chemical shift of C-9 at 87.2 p.p.m. in 2 indicated an $\mathrm{O}$-glucosidic bond. The NMR data of 2 were largely identical to previously reported lobophorin C (4) (Supplementary Table S2). In fact, the only major difference was the presence of an aldehyde residue $\left(\delta_{\mathrm{H}} 9.43\right.$ and $\left.\delta_{\mathrm{C}} 196.4\right)$ in place of a $\mathrm{CH}_{2} \mathrm{OH}$ group. The C-21 and $\mathrm{C}-22{ }^{13} \mathrm{C}$ resonances of 2 were shifted 34.3 and 3.5 p.p.m. downfield in comparison with those of 4, indicating conjugation between the aldehyde and double bond C-21-C-22. The HMBC correlations from $\mathrm{H}-32$ to $\mathrm{C}-32$ and from $\mathrm{H}-21$ to $\mathrm{C}-32$ confirmed the partial structure of the conjugated aldehyde group.

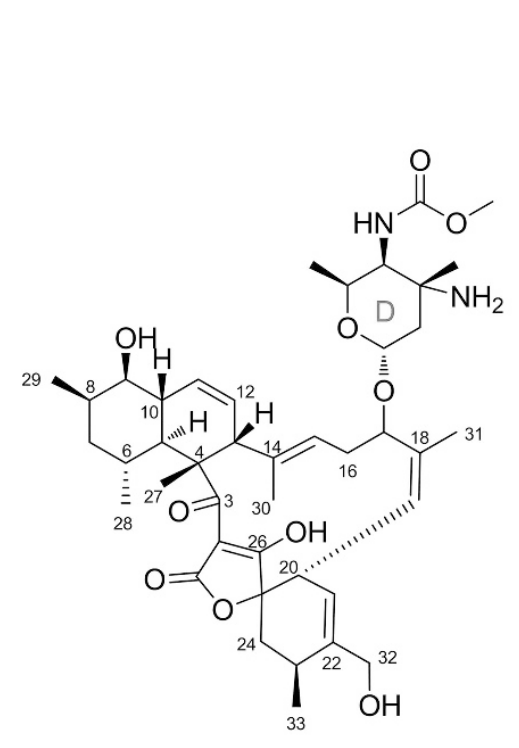

1

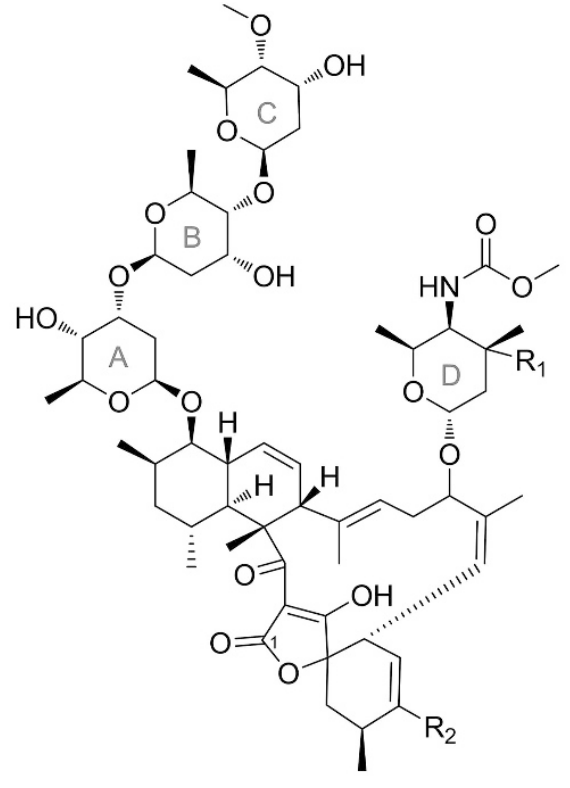

$\begin{array}{lll}2 & \mathrm{R}_{1}=\mathrm{NO}_{2} & \mathrm{R}_{2}=\mathrm{CHO} \\ 4 & \mathrm{R}_{1}=\mathrm{NO}_{2} & \mathrm{R}_{2}=\mathrm{CH}_{2} \mathrm{OH} \\ 5 & \mathrm{R}_{1}=\mathrm{NH}_{2} & \mathrm{R}_{2}=\mathrm{CH}_{2} \mathrm{OH}\end{array}$

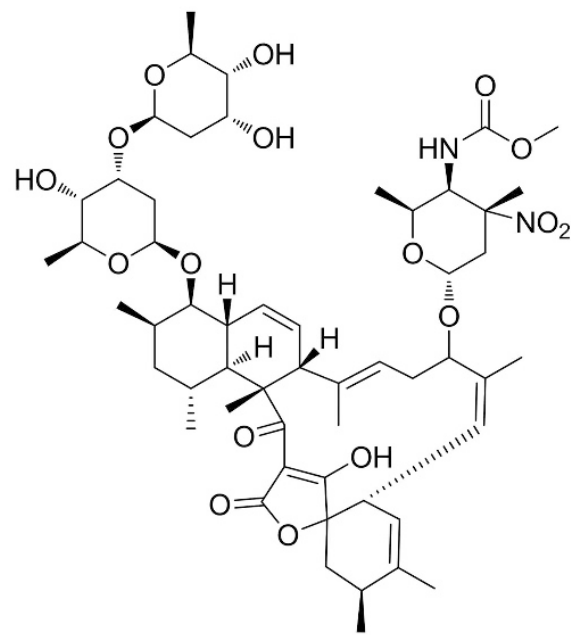

3

Figure 1 Structures of lobophorin compounds $\mathbf{1 - 5}$. 
Table $1{ }^{1} \mathrm{H}$ and ${ }^{13} \mathrm{C}$ NMR data for compounds 1 and 2

\begin{tabular}{|c|c|c|c|c|}
\hline \multirow[b]{2}{*}{ No } & \multicolumn{2}{|c|}{$1^{\mathrm{a}}$} & \multicolumn{2}{|l|}{$2^{\mathrm{b}}$} \\
\hline & $\delta_{H}(\mathrm{~J}$ in $\mathrm{Hz})$ & $\delta_{c}$ & $\delta_{H}(\mathrm{~J}$ in $\mathrm{Hz})$ & $\delta_{C}$ \\
\hline 2 & - & $103.1 \mathrm{C}$ & - & ND \\
\hline 3 & - & $204.0 \mathrm{C}$ & - & $200.5 \mathrm{C}$ \\
\hline 4 & - & $51.8 \mathrm{C}$ & - & $53.2 \mathrm{C}$ \\
\hline 7 & $1.44 \mathrm{~m}$ & $42.2 \mathrm{CH}_{2}$ & $1.49 \mathrm{~m}, 1.58 \mathrm{~m}$ & $43.9 \mathrm{CH}_{2}$ \\
\hline 8 & $2.07 \mathrm{~m}$ & $35.4 \mathrm{CH}$ & $2.20 \mathrm{~m}$ & $36.6 \mathrm{CH}$ \\
\hline 9 & $3.40 \mathrm{~m}$ & $74.9 \mathrm{CH}$ & $3.40 \mathrm{dd}(10.5,5.1)$ & $87.2 \mathrm{CH}$ \\
\hline 10 & $1.90 \mathrm{~m}$ & $39.4 \mathrm{CH}$ & 2.02 brdd $(12.0,11.0)$ & $40.7 \mathrm{CH}$ \\
\hline 11 & $6.02 \mathrm{~d}(10.0)$ & $128.0 \mathrm{CH}$ & 5.72 brd (10.2) & $127.5 \mathrm{CH}$ \\
\hline 12 & $5.28 \mathrm{~m}$ & $125.8 \mathrm{CH}$ & 5.36 ddd $(10.0,5.3,2.7)$ & $130.0 \mathrm{CH}$ \\
\hline 13 & $3.39 \mathrm{~m}$ & $52.8 \mathrm{CH}$ & 3.78 brd (4.9) & $53.3 \mathrm{CH}$ \\
\hline 18 & - & $138.6 \mathrm{C}$ & - & $139.3 \mathrm{C}$ \\
\hline 19 & $4.97 \mathrm{~d}(10.0)$ & $119.1 \mathrm{CH}$ & 5.25 brd (9.3) & $119.7 \mathrm{CH}$ \\
\hline 20 & $3.48 \mathrm{dd}(10.0,2.5)$ & $40.4 \mathrm{CH}$ & 3.63 brd (9.3) & $43.8 \mathrm{CH}$ \\
\hline 21 & 5.34 brs & $120.9 \mathrm{CH}$ & $6.66 \mathrm{brs}$ & $155.2 \mathrm{CH}$ \\
\hline 22 & - & $142.5 \mathrm{C}$ & & $146.0 \mathrm{C}$ \\
\hline 23 & $2.55 \mathrm{~m}$ & $27.7 \mathrm{CH}$ & $2.84 \mathrm{dd}(9.2,2.7)$ & $27.2 \mathrm{CH}$ \\
\hline 24 & $2.24 \mathrm{~m}, 1.75 \mathrm{~m}$ & $35.4 \mathrm{CH}_{2}$ & $2.27 \mathrm{dd}(14.5,7.5), 1.68 \mathrm{~m}$ & $36.2 \mathrm{CH}_{2}$ \\
\hline 25 & & $83.6 \mathrm{C}$ & & $85.2 \mathrm{C}$ \\
\hline 26 & & 197.6 C & & ND \\
\hline 27 & $1.44 \mathrm{~s}$ & $15.6 \mathrm{CH}_{3}$ & $1.47 \mathrm{~s}$ & $16.0 \mathrm{CH}_{3}$ \\
\hline 28 & $0.55 \mathrm{brs}$ & $23.0 \mathrm{CH}_{3}$ & $0.65 d(6.7)$ & $23.7 \mathrm{CH}_{3}$ \\
\hline 29 & $0.92 \mathrm{~d}(6.8)$ & $14.0 \mathrm{CH}_{3}$ & $1.12 \mathrm{~d}(6.5)$ & $15.3 \mathrm{CH}_{3}$ \\
\hline 30 & $1.29 \mathrm{~s}$ & $14.4 \mathrm{CH}_{3}$ & $1.37 \mathrm{~s}$ & $15.2 \mathrm{CH}_{3}$ \\
\hline A6 & & & $1.19 \mathrm{~d}(6.3)$ & $18.6 \mathrm{CH}_{3}$ \\
\hline B1 & & & 5.18 brd (3.4) & $93.9 \mathrm{CH}$ \\
\hline B2 & & & $2.09 \mathrm{~m}, 1.99 \mathrm{ddd}(15.0,3.8,3.6)$ & $36.5 \mathrm{CH}_{2}$ \\
\hline B3 & & & $4.17 \mathrm{dd}(6.3,3.6)$ & $68.8 \mathrm{CH}$ \\
\hline B4 & & & $3.28 \mathrm{dd}(9.9,3.6)$ & $84.0 \mathrm{CH}$ \\
\hline B5 & & & $4.04 \mathrm{dq}(9.4,6.6)$ & $64.4 \mathrm{CH}$ \\
\hline B6 & & & $1.19 \mathrm{~d}(6.5)$ & $18.6 \mathrm{CH}_{3}$ \\
\hline C1 & & & 4.94 brd (9.7) & $101.4 \mathrm{CH}$ \\
\hline C2 & & & $2.04 \mathrm{~m}, 1.72 \mathrm{~m}$ & $39.3 \mathrm{CH}_{2}$ \\
\hline C3 & & & $4.29 \mathrm{dd}(6.0,3.1)$ & $64.9 \mathrm{CH}$ \\
\hline C4 & & & $2.84 \mathrm{dd}(9.2,2.7)$ & $84.3 \mathrm{CH}$ \\
\hline C5 & & & $3.82 \mathrm{~m}$ & $70.5 \mathrm{CH}$ \\
\hline C6 & & & $1.22 \mathrm{~d}(6.5)$ & $19.1 \mathrm{CH}_{3}$ \\
\hline C7 & & & $3.69 \mathrm{~s}$ & $53.6 \mathrm{CH}_{3}$ \\
\hline D1 & $4.75 \mathrm{~d}(9.8)$ & $97.6 \mathrm{CH}$ & 4.52 brd (9.6) & $99.5 \mathrm{CH}$ \\
\hline D2 & $1.90 \mathrm{~m}, 1.73 \mathrm{~m}$ & $37.0 \mathrm{CH}_{2}$ & $2.71 \mathrm{brd}$ (15.0), $1.79 \mathrm{dd}(15.0 \mathrm{~m} \mathrm{9.4)}$ & $37.0 \mathrm{CH}_{2}$ \\
\hline D3 & - & $57.0 \mathrm{C}$ & - & $92.9 \mathrm{C}$ \\
\hline D4 & $3.55 \mathrm{~m}$ & $54.0 \mathrm{CH}$ & 4.35 brs & $55.8 \mathrm{CH}$ \\
\hline D5 & $3.99 \mathrm{~m}$ & $67.9 \mathrm{CH}$ & $3.52 \mathrm{q}$ & $70.7 \mathrm{CH}$ \\
\hline D6 & $1.00 \mathrm{~d}(6.2)$ & $17.6 \mathrm{CH}_{3}$ & $1.13 \mathrm{~d}(6.5)$ & $18.1 \mathrm{CH}_{3}$ \\
\hline D7 & $1.18 \mathrm{~s}$ & $24.2 \mathrm{CH}_{3}$ & $1.52 \mathrm{~s}$ & $26.3 \mathrm{CH}_{3}$ \\
\hline D8 & & $158.5 \mathrm{C}$ & - & $160.7 \mathrm{C}$ \\
\hline D9 & $3.55 \mathrm{~s}$ & $52.5 \mathrm{CH}_{3}$ & $3.68 \mathrm{~s}$ & $53.6 \mathrm{CH}_{3}$ \\
\hline
\end{tabular}




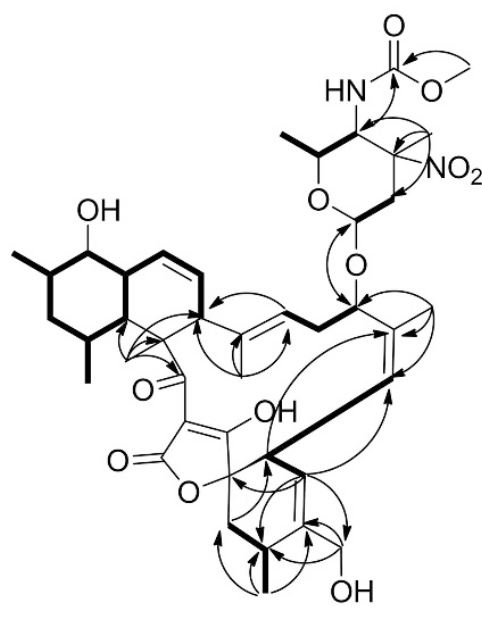

1

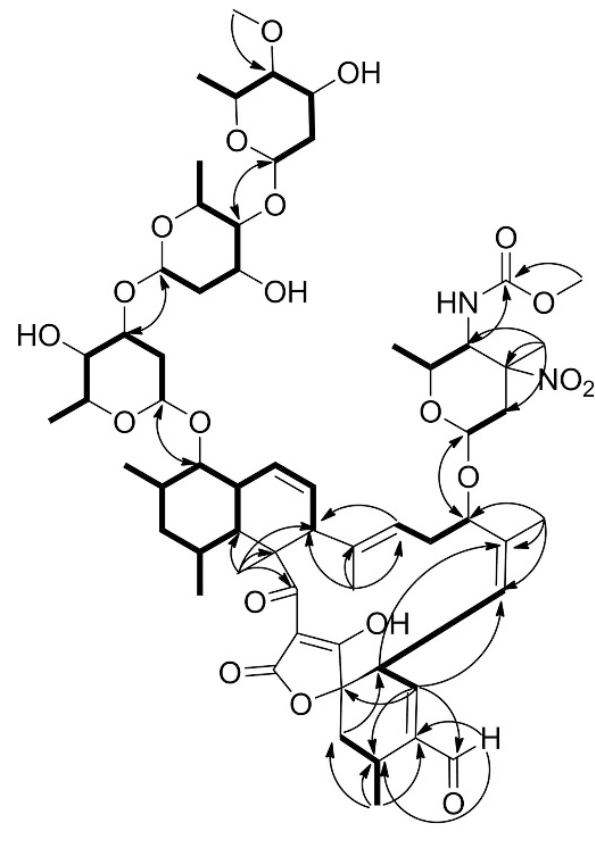

2

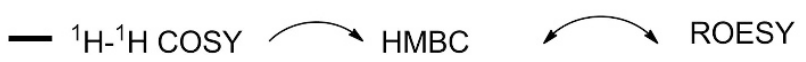

Figure 2 Key HMBC, ${ }^{1} \mathrm{H}-{ }^{1} \mathrm{H}$ COSY and ROESY correlations for compounds $\mathbf{1}$ and $\mathbf{2}$.

Table 2 Antimycobacterial activity (MIC 90 ) and CEM-TART cytotoxicity $\left(\mathrm{LD}_{50}\right)$ for compounds $1-5$

\begin{tabular}{lccccc}
\hline & $\mathbf{1}$ & $\mathbf{2}$ & $\mathbf{3}$ & $\mathbf{4}$ & $\mathbf{5}$ \\
\hline M. tuberculosis & $>100$ & 2.6 & 7.8 & 1.3 & 1.4 \\
P. aeruginosa & $>100$ & $>100$ & $>100$ & $>100$ & $>100$ \\
B. cepacia & $>100$ & $>100$ & $>100$ & $>100$ & $>100$ \\
B. subtilis & $>100$ & 10.6 & 24.4 & 1.3 & 21.6 \\
CEM-TART & $>100$ & 8.6 & 0.3 & 1.6 & 1.7 \\
\hline
\end{tabular}

Compounds $\mathbf{1} \mathbf{- 5}$ were tested for their inhibitory activity against a panel of bacteria for which further drugs are needed. All compounds except 1 showed strong inhibitory activity to $M$. tuberculosis and B. subtilis with MIC values ranging from 1.3 to $24 \mu \mathrm{M}$ (Table 2). In contrast, none of the compounds showed inhibitory activity to $P$. aeruginosa or B. cepacia. To examine the potential to develop lobophorins to treat infections, we also tested the cytotoxicity of these compounds against human CEM-TART cancer cell line. Unfortunately, all the antimycobacterial active compounds also showed strong cytotoxicity with potencies similar to those of their antimycobacterial activities (Table 2).

\section{DISCUSSION}

Lobophorins belong to a family of bacterial spirotetronates, which comprise a large class of antibiotics and antitumor agents. In addition to lobophorins, ${ }^{17-19}$ the family includes antlermicins, ${ }^{21,22}$ chlorothricin, ${ }^{23}$ kijanimicin, ${ }^{24}$ decatromicins, ${ }^{25}$ saccharocarcins, ${ }^{26}$ tetrocarcins ${ }^{27}$ and versipelostatins. ${ }^{28}$ We tested the new isolated lobophorin derivatives against a panel of bacteria. Of note, we found that the lobophorins are relatively potent against mycobacteria: compounds $\mathbf{4}$ and $\mathbf{5}$ were about $4 \times$ less potent than rifampicin control. Very recently, other members of this series were also tested for their activity on M. tuberculosis. ${ }^{20}$ We show that the antimycobacterial compounds also exhibit toxicity to human cells, limiting their potential utility.

Some interesting structure-activity relationships were observed, which might be useful in designing more selective antimycobacterial agents. Derivative 1 lacks the three digitoxose sugar moieties, and concomitantly also lacks activity against $M$. tuberculosis and human cells. Loss of one of the digitoxose units, as in compound 3, led to a $>25$-fold selective toxicity to human vs $M$. tuberculosis cells. Compounds $\mathbf{4}$ and $\mathbf{5}$ have nearly equal potency to both cell types. By contrast, new compound 2, which contains an $\alpha, \beta$-unsaturated aldehyde, provided a $>3$-fold selectivity for antitubercular activity vs cytotoxicity. This finding suggests that simple modifications of the lobophorin scaffold may provide derivatives that are selective antimicrobial agents. Recently, biosynthetic gene clusters for lobophorins and its polyketide relatives have been described, providing a platform for engineering to produce desired derivatives. ${ }^{29-31}$ Interestingly, elucidation of the glycosylation steps shows definitively that compounds similar to $\mathbf{1}$ are precursors to other compounds in the series.

Many novel metabolites have been discovered in marine actinomycetes, ${ }^{32}$ although arguably most of the metabolites so far discovered fall into structural categories that are very similar to those of their terrestrial relatives. Even so, discovery of related derivatives have been very useful in the development of therapeutic agents. Examples include salinisporamide, ${ }^{33,34}$ which is structurally related to omuralide ${ }^{35}$ but that has features making it highly novel in its mode of action. Lomaiviticin ${ }^{36}$ provides another example where a 
play on a biosynthetic theme has led to a series of quite different molecules. A novel, but structurally trivially new bottromycin ${ }^{37}$ derivative was found in an ascidian-associated Streptomyces strain; the bottromycin biosynthetic gene cluster was relatively divergent (about 85\% DNA sequence identity) in comparison with those found in several terrestrial strains, which has some biotechnological application in the creation of derivatives. However, not all marine strains differ from terrestrial relatives genetically, and even those that have specific associations with marine invertebrates may be nearly identical to terrestrial strains. For example, it was found that a Nocardiopsis strain living in close association with a cone snail is genomically nearly identical to a strain that lives with bees. ${ }^{9}$ Therefore, accessing actinomycetes from the marine environment, including marine animals, has demonstrated utility in finding both novel strains and novel metabolites, including some in clinical trials. ${ }^{34}$ Those strains and metabolites are related to those found on land, and are sometimes even identical, but nonetheless novel derivatives have been extremely useful in drug discovery.

A current area of research interest is the determination of whether many of these actinomycetes are specifically found in the marine environment and whether they are associated with animals. A wealth of data shows that Salinispora spp. are marine-specific strains. ${ }^{38}$ Much less data are available concerning potential interactions of marine actinomycetes with marine animals. In at least the case of the cone snails described above, one strain seems to live specifically with animals, although it is identical to a terrestrial strain..$^{9}$ Lumun-lumun collection provides rapid access to diverse micromollusks, including many new species. Because many related species are conveniently obtained from the same habitat in a single net, lumun-lumun provides a method to answer questions about the specific interactions of marine bacteria, including actinomycetes, with host animals. This method was also shown to be of utility in providing rapid access to diverse, novel and bioactive venom peptides that might find therapeutic application. ${ }^{12}$ Here, and in a recent report on structurally novel compounds, we show that this method leads to discovery of both highly novel compounds and a series of trivial derivatives, the lobophorins, which has led to an interesting structure-activity relationship series.

\section{MATERIALS AND METHODS}

\section{General experimental procedures}

UV spectra were obtained using a Perkin-Elmer Lambda2 UV/vis spectrometer. The NMR data were collected using either a Varian (Palo Alto, CA, USA) INOVA $500\left({ }^{1} \mathrm{H} 500 \mathrm{MHz},{ }^{13} \mathrm{C} 125 \mathrm{MHz}\right)$ NMR spectrometer with a 3-mm Nalorac MDBG probe or a Varian INOVA $600\left({ }^{1} \mathrm{H} 600 \mathrm{MHz},{ }^{13} \mathrm{C} 150 \mathrm{MHz}\right)$ NMR spectrometer equipped with a $5-\mathrm{mm}{ }^{1} \mathrm{H}\left[{ }^{13} \mathrm{C},{ }^{15} \mathrm{~N}\right]$ triple resonance cold probe with a z-axis gradient, utilizing residual solvent signals for referencing. High-resolution mass spectra (HRESIMS) were obtained using a Bruker (Billerica, MA, USA) APEXII FTICR mass spectrometer equipped with an actively shielded 9.4-T superconducting magnet (Magnex Scientific Ltd., Oxford, UK), an external Bruker APOLLO ESI source, and a Synrad (Mukilteo, WA, USA) $50 \mathrm{~W} \mathrm{CO}_{2} \mathrm{CW}$ laser. Supelco (St Louis, MO, USA) Discover HS $(4.6 \times 150 \mathrm{~mm})$ and semipreparative $(10 \times 150 \mathrm{~mm}) \mathrm{C}_{18}(5 \mu \mathrm{m})$ columns were used for analytical and semipreparative HPLC, respectively, as conducted on a Hitachi (Dallas, TX, USA) Elite Lachrom System equipped with a Diode Array L-2455 detector. Antibacterial and cytotoxicity assay plates were evaluated by measuring $A_{580}$ on a Multiskan FC plate reader (Fisher Scientific, Waltham, MA, USA). Chemicals were sourced from Sigma-Aldrich (St Louis, MO, USA) or Fisher Scientific with the exception of the following: fetal bovine serum was obtained from Atlanta Biologicals (Lawrenceville, GA, USA), ADC supplement from Remel (Lenexa, KS, USA), and antimycotic/antibacterial supplement from MP Biomedicals (Solon, OH, USA).

\section{Bacterial material}

Bacteria were cultivated from $L$. totopotens obtained by professional collectors near Mactan Island, Cebu, Philippines as previously described. ${ }^{11}$ Relevant permission from local and national authorities in the Philippines was obtained before beginning this study. Streptomyces sp. 1053U.I.1a.3b was obtained from dissected hepatopancreas tissue, purified into an axenic culture, and stored as a glycerol stock at $-80^{\circ} \mathrm{C}$. The strain was subsequently recovered from a glycerol stock and used for further chemical analysis. The $16 \mathrm{~S}$ gene was cloned using primers 8-27f (5'-AGAGTTTGATCCTGGCTCAG-3') and 1492r (5'-TACGGYTACCTTGTTACGA CTT- $3^{\prime}$ ) and submitted to GenBank (accession number KF137580).

\section{Fermentation and extraction}

For the first-stage seed, an agar grown culture of Streptomyces sp. 1053U.I.1a.3b was inoculated into $150 \mathrm{ml}$ of ISP2 medium ( $0.4 \%$ yeast extract, $1 \%$ malt extract, $0.4 \%$ glucose, $2 \% \mathrm{NaCl}$ ). After 3 days incubation at $22^{\circ} \mathrm{C}$ with shaking, the first stage $(100 \mathrm{ml})$ was used to inoculate in a New Brunswick BioFlo1 10 fermenter containing 101 of the medium ISP2 at $30^{\circ} \mathrm{C}$. After 8 days, the broth was centrifuged and the supernatant was extracted with Diaion HP20 resin for $4 \mathrm{~h}$. The resin was filtered through cheesecloth and washed with $\mathrm{H}_{2} \mathrm{O}$ to remove salts. The filtered resin was eluted with $\mathrm{MeOH}$ to yield a primary extract.

\section{Purification}

The primary extract $(300 \mathrm{mg}$ ) was dissolved in $2 \mathrm{ml} \mathrm{MeOH}$ and then saturated with RP18 silica gel $(2 \mathrm{~g})$. The RP18 silica gel with extract was dried under vacuum and load on a glass column with RP18 silica gel $(5 \mathrm{~g})$. The column was first flushed with $50 \mathrm{ml} \mathrm{H}_{2} \mathrm{O}$, and followed by four more washes using stepgradient elution of $\mathrm{MeOH}$ in $\mathrm{H}_{2} \mathrm{O}$ (40,60, 70 and $80 \% ; 100 \mathrm{ml}$ each), leading to four fractions ( $\mathrm{Fr} 1-\mathrm{Fr} 4)$. Fr3 eluted in $70 \% \mathrm{MeOH}$ and was further fractionated by $\mathrm{C}_{18}$ HPLC using $68 \% \mathrm{MeOH}$ in $\mathrm{H}_{2} \mathrm{O}$ with $0.05 \%$ TFA to obtain pure compounds $3(1.5 \mathrm{mg}), 4(2.0 \mathrm{mg})$, and a fraction Fr3.2 containing compounds 2 and 5, Fr3.2 was further purified by $\mathrm{C}_{18}$ HPLC using $65 \%$ $\mathrm{MeOH}$ in $\mathrm{H}_{2} \mathrm{O}$ with $0.05 \%$ TFA to obtain compounds $2(1.1 \mathrm{mg})$ and 5 $(0.9 \mathrm{mg})$. Fr4 eluted in $80 \% \mathrm{MeOH}$ and was further purified by $\mathrm{C}_{18}$ HPLC using $75 \% \mathrm{MeOH}$ in $\mathrm{H}_{2} \mathrm{O}$ with $0.05 \%$ TFA to obtain compound 1 (1.3 mg).

\section{Lobophorin H (1)}

Colorless solid; UV $(\mathrm{MeOH}) \lambda_{\max } 204,241,267 \mathrm{~nm} ;{ }^{1} \mathrm{H}$ and ${ }^{13} \mathrm{C}$ NMR (see Table 1); HRESIMS $\mathrm{m} / \mathrm{z} 753.4344[\mathrm{M}+\mathrm{H}]^{+}$(calcd for $\mathrm{C}_{42} \mathrm{H}_{61} \mathrm{~N}_{2} \mathrm{O}_{10}$, 753.4326).

\section{Lobophorin I (2)}

Colorless solid; UV (MeOH) $\lambda_{\max } 204,241,267 \mathrm{~nm} ;{ }^{1} \mathrm{H}$ and ${ }^{13} \mathrm{C}$ NMR (see Table 1); HRESIMS $m / z 1185.5962[\mathrm{M}+\mathrm{H}]^{+}$(calcd for $\mathrm{C}_{61} \mathrm{H}_{89} \mathrm{~N}_{2} \mathrm{O}_{21}$, 1185.5958).

\section{B. subtilis disk assay}

B. subtilis ATCC 6633 was plated on Mueller-Hinton agar media. Compounds and controls were added to paper disks at varying concentrations, and zones of inhibition were detected by eye.

\section{Antimicrobial broth dilution assays}

The assay was performed as previously described, ${ }^{39}$ with the exception that four wells per compound were used for each dilution for MIC determination. DMSO served as a negative control. Bacterial strains used, along with the positive control antibiotic for each strain, were M. tuberculosis H37Ra (rifampicin); P. aeruginosa ATCC 27853 (gentamicin); B. subtilis ATCC 6633 (gentamicin); and B. cepacia ATCC 25608 (chloramphenicol).

\section{Cytotoxicity assay}

Cytotoxicity testing was performed using CEM-TART lymphoblastoid cells ${ }^{40}$ cultured in RPMI-1640 with $20 \%$ fetal bovine serum and antibiotic/ antimycotic supplement at $37^{\circ} \mathrm{C}$ with $5 \% \quad \mathrm{CO}_{2}$ in moisture saturated atmosphere in 96-well culture clusters. Test compounds dissolved in $1 \mu \mathrm{l}$ 
DMSO, negative controls (DMSO alone) or positive controls (doxorubicin in DMSO) were added in triplicate wells together with 50000 cells in $200 \mu \mathrm{l}$ of fresh media and incubated for $72 \mathrm{~h}$. Each well then received $11 \mu \mathrm{lof} 5 \mathrm{mg} \mathrm{ml}^{-1}$ MTT (Sigma, St Louis, MO, USA) followed by $2 \mathrm{~h}$ incubation after which the formazan precipitate was pelleted by centrifugation. The spent media was aspirated and the formazan crystals solubilized in DMSO. Absorbance at $580 \mathrm{~nm}$ was quantified on a Multiskan FC (Fisher Scientific) plate reader and inhibition determined as described in the antimycobacterial assay procedure.

\section{ACKNOWLEDGEMENTS}

Collection, cultivation, isolation and chemical characterization were funded by ICBG grant U01TW008163 from Fogarty (NIH). We thank the government of the Philippines and the community of Mactan Island for permission to conduct this study. Bioassay work was funded by ICBG grant U01T006671 from Fogarty (NIH). CEM-TART cells were obtained through the NIH AIDS Reagent Program, Division of AIDS, NIAID, NIH—Drs Herbert Chen, Terence Boyle, Michael Malim, Bryan Cullen, and H. Kim Lyerly.

1 Lewis, K. Platforms for antibiotic discovery. Nat. Rev. Drug. Discov. 12, 371-387 (2013).

2 Tuberculosis Fact Sheet No 104 (2013) (Accessed at http://www.who.int/mediacentre/ factsheets/fs104/en/).

3 Klopper, M. et al. Emergence and spread of extensively and totally drug-resistant tuberculosis, South Africa. Emerg. Infect. Dis. 19, 449-455 (2013).

4 Zumla, A., Nahid, P. \& Cole, S. T. Advances in the development of new tuberculosis drugs and treatment regimens. Nat. Rev. Drug. Discov. 12, 388-404 (2013).

5 Antibiotic resistance threats in the United States (2013) (Accessed at http:// www.cdc.gov/drugresistance/threat-report-2013/).

6 Lin, Z. et al. Neuroactive thiazoline metabolites from cone snail-associated bacteria. $J$. Nat. Prod. 73, 1922-1926 (2010)

7 Lin, Z. et al. long-acting transient receptor potential vanilloid-1 (TRPV1) antagonists from mollusk-associated bacteria. J. Med. Chem. 54, 3746-3755 (2011).

8 Lin, Z. et al. Totopotensamides, polyketide-cyclic peptide hybrids from a molluskassociated bacterium Streptomyces sp. J. Nat. Prod. 75, 644-649 (2012).

9 Lin, Z. et al. A bacterial source for mollusk pyrone polyketides. Chem. Biol. 20, 73-81 (2013).

10 Lin, Z et al. Neuroactive diol and acyloin metabolites from cone snail-associated bacteria. Bioorg. Med. Chem. Lett. 23, 4867-4869 (2013).

11 Peraud, 0. et al. Microhabitats within venomous cone snails contain diverse actinobacteria. Appl. Environ. Microbiol. 75, 6820-6826 (2009).

12 Seronay, R. A. et al. Accessing novel conoidean venoms: Biodiverse lumun-lumun marine communities, an untapped biological and toxinological resource. Toxicon 56 1257-1266 (2010)

13 Rosenberg, G. \& Stahlschmidt, P. A new species of Lienardia (Gastropoda: Conoidea) from the Philippines and the Spratly Islands. Proc. Acad. Nat. Sci. Philadephia 161, 105-115 (2011)

14 Kilburn, R. N., Fedosov, A. E. \& Olivera, B. M. Revision of the genus Turris Batsch, 1789 (Gastropoda: Conoidea: Turridae) with the description of six new species. Zootaxa 244, 1-58 (2012).

15 Fedosov, A. et al. Phylogeny of the genus Turris: correlating molecular data with radular anatomy and shell morphology. Mol. Phylogenet. Evol. 59, 263-270 (2011).

16 Olivera, B. M. et al. Adaptive radiation of venomous marine snail lineages and the accelerated evolution of venom peptide genes. Ann. N Y Acad. Sci. 1267, 61-70 (2012)
17 Jiang, Z. D., Jensen, P. R. \& Fenical, W. Lobophorins A and B, new antiinflammatory macrolides produced by a tropical marine bacterium. Bioorg. Med. Chem. Lett. 9 , 2003-2006 (1999).

18 Wei, R. B. et al. Lobophorin C and D, new kijanimicin derivatives from a marine sponge-associated actinomycetal strain AZS17. Mar. Drugs 9, 359-368 (2011).

$19 \mathrm{Niu}, \mathrm{S}$. et al. Lobophorins E and F, new spirotetronate antibiotics from a South China Sea-derived Streptomyces sp. SCSIO 01127. J. Antibiot. 64, 711-716 (2011).

20 Chen, C. et al. Three antimycobacterial metabolites identified from a marine-derived Streptomyces sp. MS100061. Appl. Microbiol. Biotechnol 97, 3885-3892 (2013).

21 Kobinata, K., Uramoto, M., Mizuno, T. \& Isono, K. Antlermicins B and C, new members of the antlermicin family. J. Antibiot. 33, 772-775 (1980).

22 Kobinata, K., Uramoto, M., Mizuno, T. \& Isono, K. A new antibiotic, antlermicin A. J. Antibiot. 33, 244-246 (1980).

23 Muntwyler, R. \& Keller-Schierlein, W. Metabolic products of microorganisms. 107 Structure of chlorothricin, a new type of macrolide antibiotic. Helv. Chim. Acta 55 2071-2094 (1972).

24 Waitz, J. A. et al. Kijanimicin (Sch 25663), a novel antibiotic produced by Actinomadura kijaniata SCC 1256. Fermentation, isolation, characterization and biological properties. J. Antibiot. 34, 1101-1106 (1981).

25 Momose, I. et al. Decatromicins A and B, new antibiotics produced by Actinomadura sp. MK73-NF4. II. Structure determination. J. Antibiot. 52, 787-796 (1999).

26 Hegde, V. R., Patel, M. G., Das, P. R., Pramanik, B. \& Puar, M. S. A family of nove macrocyclic lactones, the saccharocarcins produced by Saccharothrix aerocolonigenes subsp. antibiotica. II. Physico-chemical properties and structure determination. I. Antibiot. 50, 126-134 (1997).

27 Tamaoki, T. et al. Tetrocarcins, novel antitumor antibiotics. II. Isolation, characterization and antitumor activity. J. Antibiot. 33, 946-950 (1980).

28 Park, H. R., Chijiwa, S., Furihata, K., Hayakawa, Y. \& Shin-Ya, K. Relative and absolute configuration of versipelostatin, a down-regulator of molecular chaperone GRP78 expression. Org. Lett. 9, 1457-1460 (2007).

$29 \mathrm{Li}$, S. et al. Dissecting glycosylation steps in lobophorin biosynthesis implies an iterative glycosyltransferase. Org. Lett. 15, 1374-1377 (2013).

30 Ding, W. et al. Insights into bacterial 6-methylsalicylic acid synthase and its engineering to orsellinic acid synthase for spirotetronate generation. Chem. Biol. 17, 495-503 (2010).

31 Xiao, J. et al. Characterization of the sugar-O-methyltransferase LobS1 in lobophorin biosynthesis. Appl. Microbiol. Biotechnol. 97, 9043-9053 (2013).

32 Subramani, R. \& Aalbersberg, W. Marine actinomycetes: an ongoing source of nove bioactive metabolites. Microbiol. Res. 167, 571-580 (2012).

33 Reed, Katherine A. et al. Salinosporamides D-J from the marine actinomycete salinispora tropica, bromosalinosporamide, and thioester derivatives are potent nhibitors of the 20S proteasome. J. Nat. Prod. 70, 269-276 (2007).

34 Gulder, Tobias A. M. \& Moore, Bradley S. Salinosporamide natural products: potent $20 \mathrm{~S}$ proteasome inhibitors as promising cancer chemotherapeutics. Angew. Chem. Int Ed. Engl. 49, 9346-9367 (2010).

35 Corey, E. J. \& Li, W. D. Total synthesis and biological activity of lactacystin, omuralide and analogs. Chem. Pharm. Bull. 47, 1-10 (1999).

36 Woo, C. M., Beizer, N. E., Janso, J. E. \& Herzon, S. B. Isolation of lomaiviticins C-E, transformation of lomaiviticin $C$ to lomaiviticin $A$, complete structure elucidation of lomaiviticin A, and structure-activity analyses. J. Am. Chem. Soc. 134, 15285-15288 (2012).

$37 \mathrm{Hou}$, Y. et al. Structure and biosynthesis of the antibiotic bottromycin D. Org. Lett. 14 5050-5053 (2012)

38 Prieto-Davo, A. et al. Targeted search for actinomycetes from nearshore and deep-sea marine sediments. FEMS Microbiol. Ecol. 84, 510-518 (2013).

39 Koch, M., Bugni, T. S., Sondossi, M., Ireland, C. M. \& Barrows, L. R. Exocarpic acid inhibits mycolic acid biosynthesis in Mycobacterium tuberculosis. Planta Med. 76 1678-1682 (2010)

40 Chen, H., Boyle, T. J., Malim, M. H. Cullen, B. R \& Lyerly, H. K. Derivation of a biologically contained replication system for human immunodeficiency virus type 1 . Proc. Natl Acad. Sci. USA 89, 7678-7682 (1992)

Supplementary Information accompanies the paper on The Journal of Antibiotics website (http://www.nature.com/ja) 